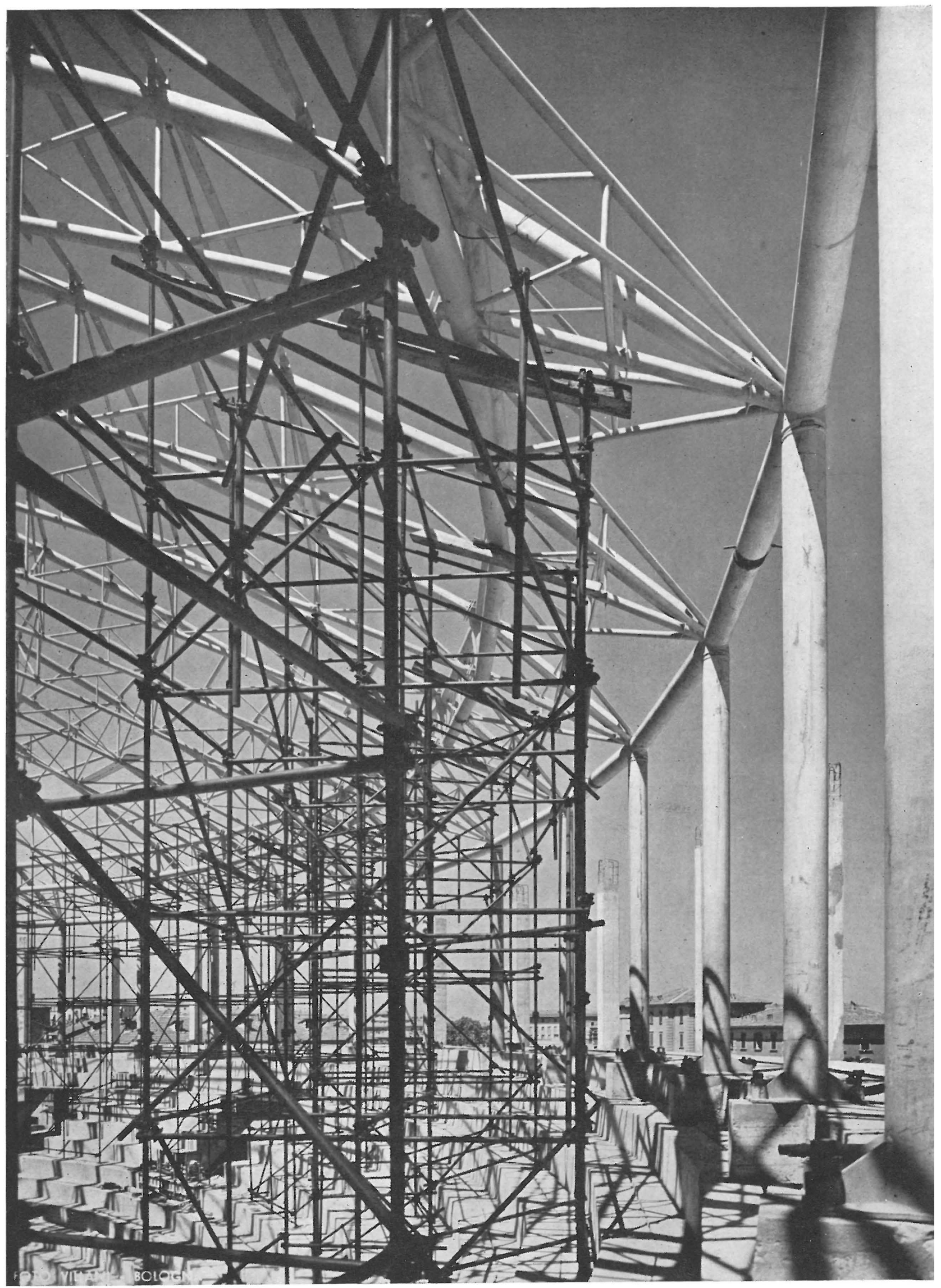

\title{
palacio de los deportes, en Bolonia
}




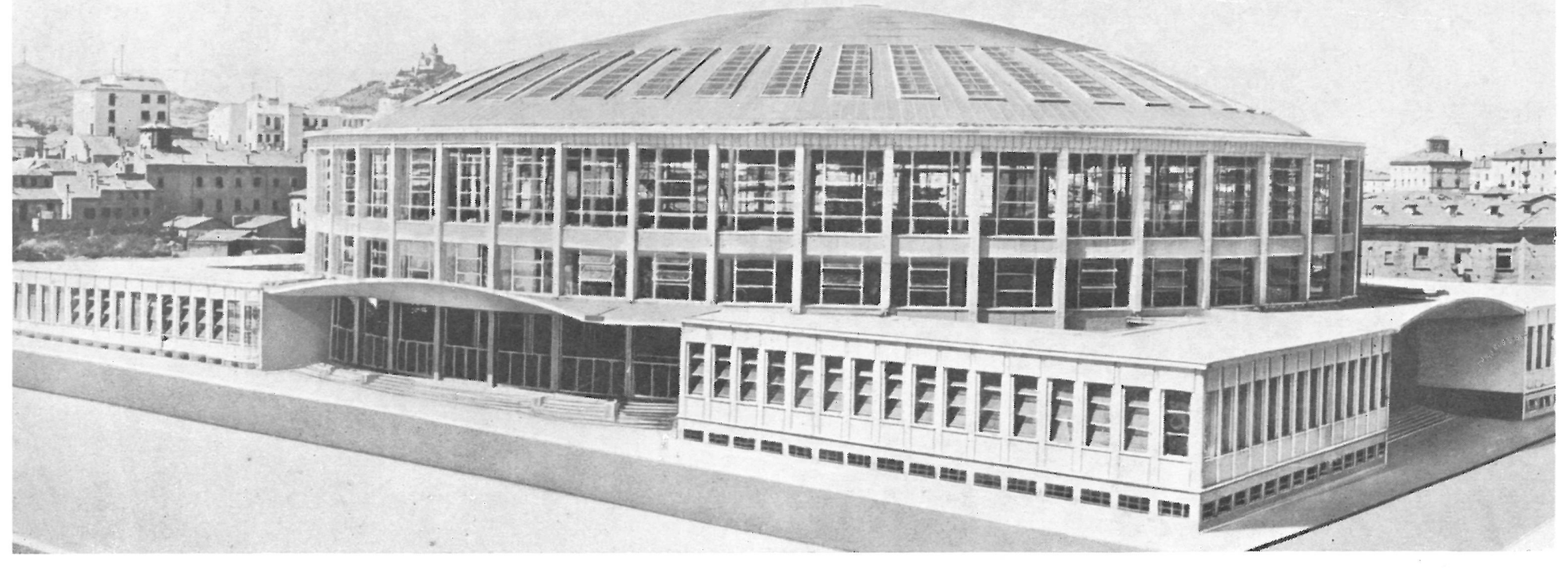

Como consecuencia de los acuerdos del Comité Olímpico Nacional Italiano, se ha construído, recientemente, en Bolonia, sobre los terrenos a tal objeto cedidos por el Ayuntamiento de aquella ciudad italiana, un amplio palacio de deportes.

La cancha de este edificio cubierto podrá transformarse en pistas para tenis, baloncesto, hockey sobre patines, patinaje, boxeo, gimnasia, conciertos, etc.

El cuerpo de este edificio, enclavado en la parte central que dejan cuatro edificaciones anexas, situadas en los vértices de una forma rectangular en planta, es del tipo cilíndrico, de tres plantas, de unos $70 \mathrm{~m}$ de diámetro, y se ha cubierto con una gran cúpula revestida en su trasdós, provisto de una banda casi continua de lucernarios trapezoidales, con chapa de aluminio.

Dispone el palacio de un graderío, capaz de 5.000 localidades sentadas en el caso de competiciones deportivas y de unas 7.000 si se trata de boxeo, conciertos u otro tipo similar de espectáculo (Los bancos del graderío se han subdividido a razón de 0,50 m por espectador).

En cada una de las tres plantas superiores corre un pasillo anular que da acceso a los distintos vomitorios de acceso al graderío. La iluminación natural del edificio es magnífica, como resultado de la gran cristalera de cierre entre la tercer planta y la cúpula, la banda de lucernarios en los arranques de la cubierta y el gran lucernario central.

La parte del interior del edificio dedicada al graderío se ha subdividido en tres partes, de tipo general, correspondientes a tres rampas, y como formando un cuarto nivel en altura, la zona reservada a la tribuna presidencial, periodistas, radio, otros servicios especiales e invitados.

Los bancos que forman los asientos son de madera; los pasillos se han pavimentado con un compuesto a base de goma. El parapeto de la zona más baja del graderío es de cristal.

Durante las manifestaciones nocturnas, el graderío se ha iluminado artificialmente con luz indirecta que parte de los propios lucernarios; la cancha se ilumina con reflectores, distribuídos en forma de constelación en la cubierta y que proyectan la luz sobre la superficie de juego directamente.

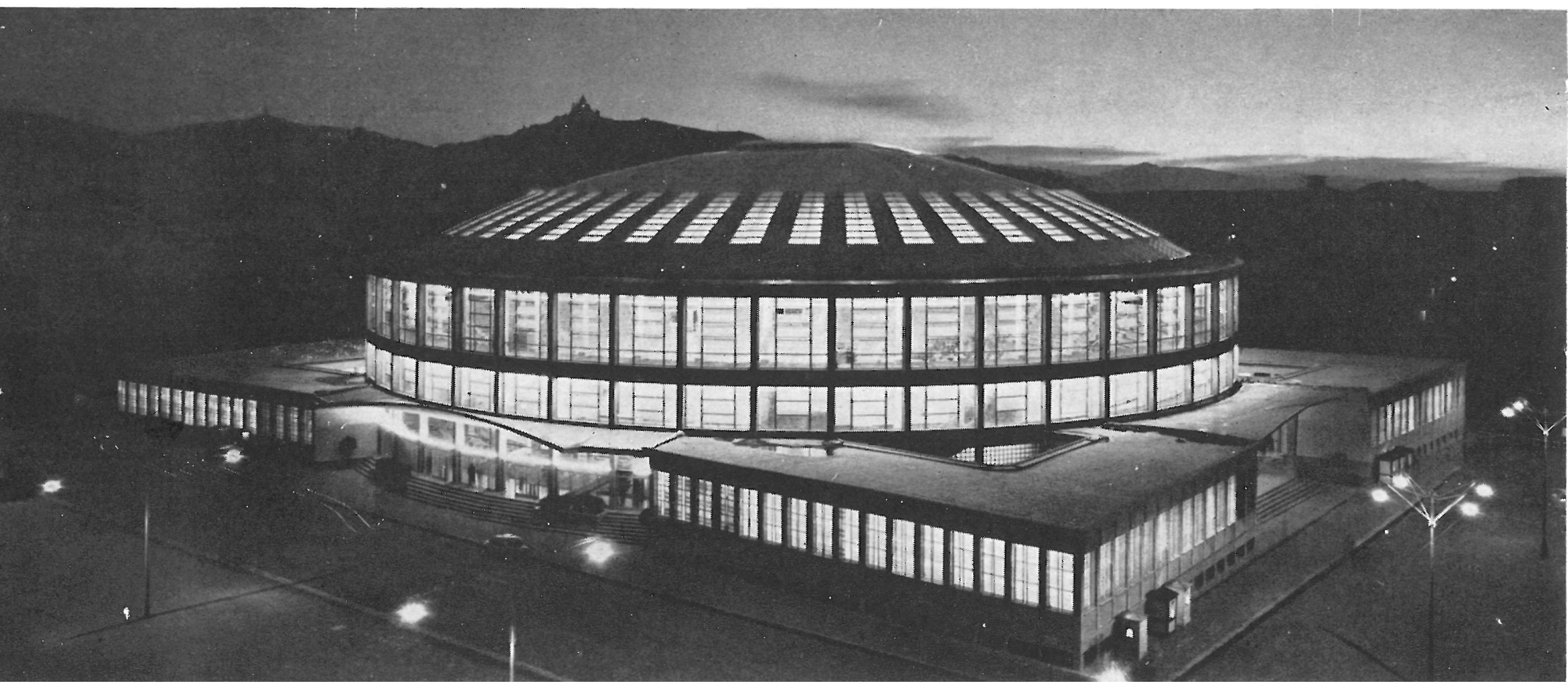




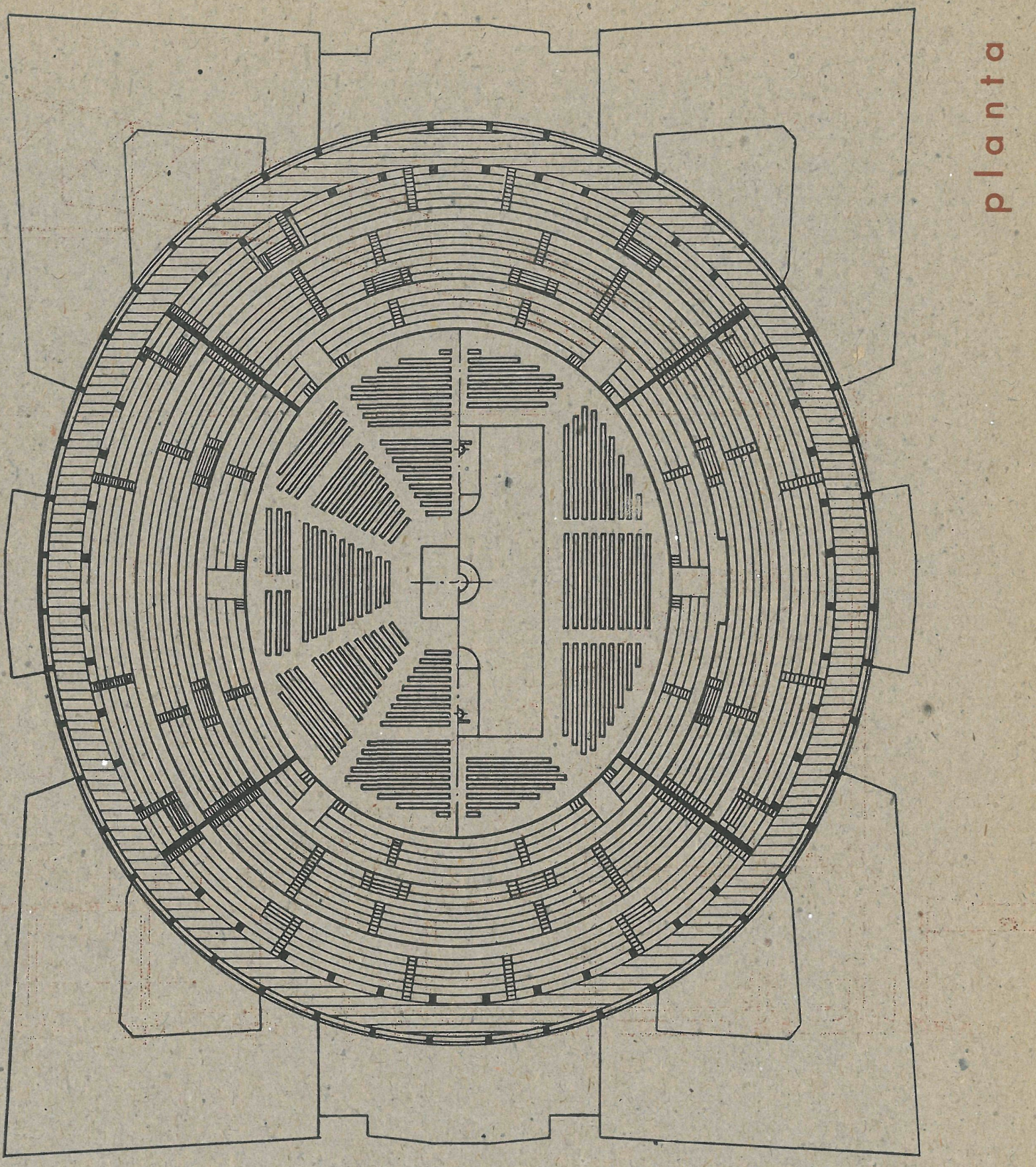

Tanto la iluminación natural como la artificial ha sido objeto de un detenido y cuidadoso estudio para hallar la mejor solución.

La superficie cubierta está limitada por una curva policéntrica, de forma muy parecida a una elipse de $68,80 \mathrm{~m}$ de eje mayor y $62 \mathrm{~m}$ para el eje menor. La curva plana tiene cuatro centros distintos y otros tantos
segmentos de circunferencia, dos de $29.755 \mathrm{~m}$ y otros dos de 39.045 metros.

La elipse geométrica de ejes equivalentes se ha rebajado al emplear los cuatro arcos de circunferencia, pero la diferencia de distancias al centro entre una y otra curva es sólo del $1,1 \%$ del radio, valor que es prácticamente inapreciable. Sin embargo, este nuevo tipo de perimetro policéntrico ha permitido una notable economía al simplificar notablemente la construcción de los semiarcos de la cúpula, ya que éstos han resultado de dos solos tipos: uno en correspondencia con el eje mayor, y el otro, con el eje menor; pero todos distintos en cada uno
de estos tipos.

Las cabezas superiores e inferiores de las cerchas tubulares o arcos radiales de la củpula están formadas por arcos parabólicos, es decir, que la superficie resultante es la de un paraboloide-elíptico. Estos arcos parabólicos están muy rebajados; asi, en el centro, tienen una flecha de $7 \mathrm{~m}$ entre intradós e imposta. El arco o cercha tiene, en el centro, una altura de $3 \mathrm{~m}$, la cual va disminuvendo para terminar anulándose en el plano de imde lo que resulta que en la parte central hay. la mitad de cerchas que en el anillo perimetral o zuncho.

A lo largo del contorno de la cúpula va un anillo, el cual absorbe el empuje horizontal de las cerchas, en tal forma, que, sin efecto del viento, los soportes sostienen la cubierta trabajando únicamente en el sentido de la vertical, pero, no obstante, han de har frente a otros empujes más modestos que se derivan de las defo:maciones de carácter térmico y las producidas por el propio peso de la estructura.

El anillo de referencia, o corona de sección transversal triangular, está constituído por dos anillos tubula. res hacia el interior, los cuales forman una cara de la corona, y otro, exterior perimetral, o arista opuesta a esta cara. 


\section{sección}

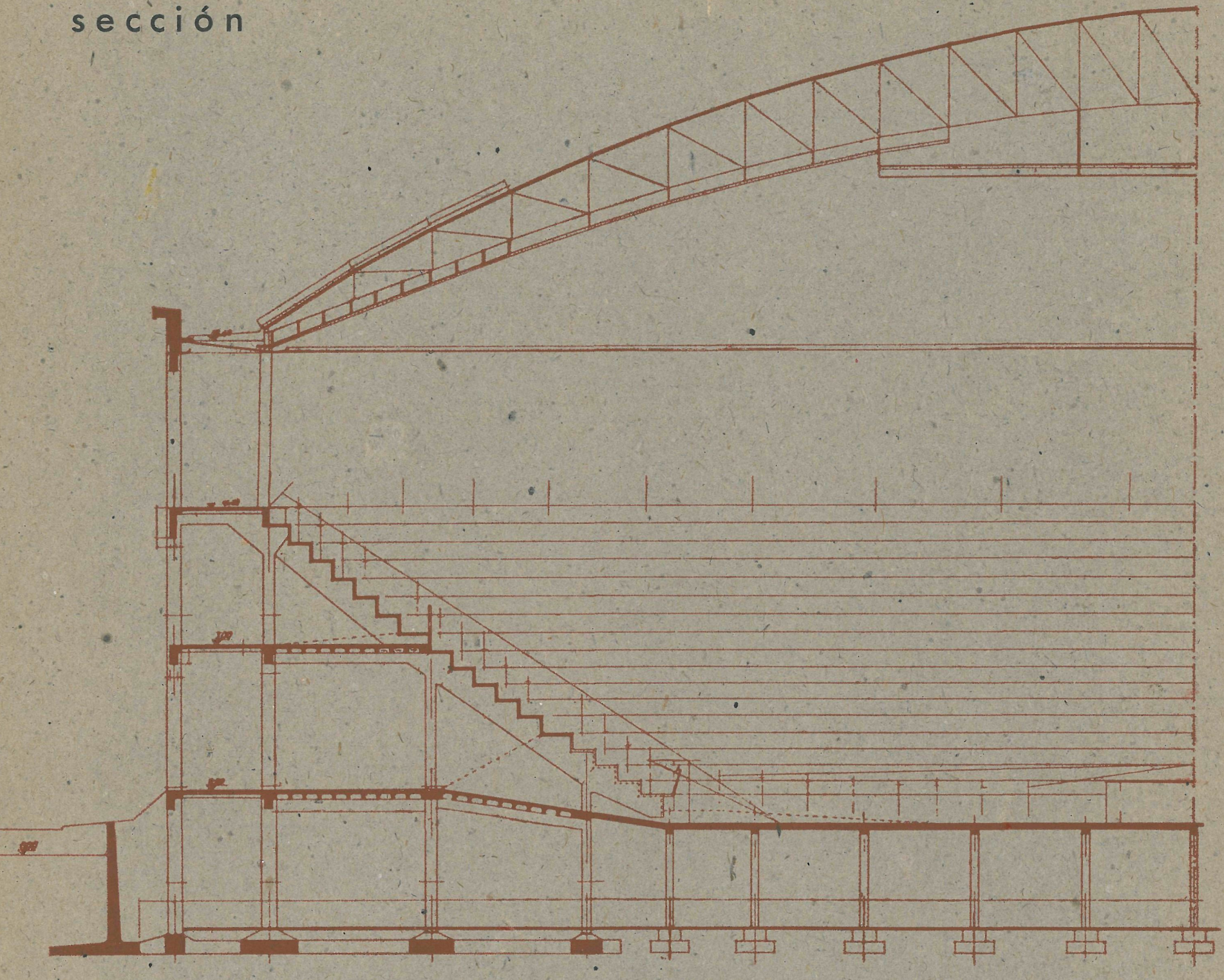

En las tres caras correspondientes a cada lado en la sección triangular de la corona se han dispuesto los elementos tubulares constituyendo un rígido arriostramiento triangulado. La corona tiene 2,50 $\mathrm{m}$ de anchura en planta; y su desarrollo, $208 \mathrm{metros}$.

Bajo ta extremidad de cada cercha se halla un soporte tubular, unido al arco articuladamente. El número de estos soportes es 48 , espaciados a $4,30 \mathrm{~m}$ en la zona del eje mayor y 4,20 en la del menor. Los montantes o pilares perimetrales exteriores se han mantenido equidistantes y a una altura constante entre plantas de $5,30 \mathrm{~m}$. En la base, estos elementos se han empotrado en là estructura de cimientos.

Las cerchas son planas, y sus nudos, tanto en el cordòn superior como los del inferior, se han unido con diagonales cruzadas. Cuatro pares de cerehas se han rigidizado entre si con elementos dispuestos en la superficie del trasdós. Correspondiendo con los puntos de bifurcación de las cerchas se ha montado un anillo de arriostramiento, dejando, sin embargo, suficiente libertad a las cerchas para dilatarse en el sentido radial y transmitir cl empuje a la corona perimetral o zuncho de sección triangular.

Sobre los cordones superiores de las cerchas se apoya el sistema de correas que sostienen los materiales de cerramiento de la cúpula, es decir, un entablado de $3 \mathrm{~cm}$ de espesor, fieltro alquitranado y la chapa final de aluminio. En los cordones inferiores, o intradós, se apoyan otras correas encargadas de suspender el techo visto del interior de la cúpula.

La superficie total de la cubierta es de 3.400 metros cuadrados.

Las cerchas tienen dos articulaciones. Se ha eliminado el empuje en el zuncho perimetral, pues funciona como un cable flexible, por lo que se ha tenido en cuenta en el cálculo el alargamiento derivado de la carga sobre el zuncho.

- El zuncho perimetral, de sección triangular, se ha dimensionado para resistir al empuje horizontal dé los arcos. El cálculo de su resistencia se ha basado en la gran flexibilidad del anillo en el plano horizontal comparada con la rigidez de las cerchas, teniendo en cuenta que todos los arcos se han unido rigidamente entre ellos en la parte central de la cúpula.

Al haber rebajado igualmente en el centro, se carga más en los arcos cortos que en los largos y aumenta el empuje horizontal de los primeros; esto proporciona una tendencia hacia la circulación de la elipse, por lo que el zuncho no reacciona a flexión en el plano horizontal, restableciéndose el equilibrio con deformaciones ligeras diversas en los extremos de los dos ejes. Con sobrecarga sólo sobre la mitad de la cúpula, el empuje horizontal de los arcos también se reduce a la mitad, por lo que este caso no presenta interés. La hipótesis comprobada con una sobrecarga que se extiende a las tres cuartas partes de la cúpula, el empuje horizontal es diferente en dos direcciones normales.

. es diferente en dos direcion

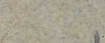



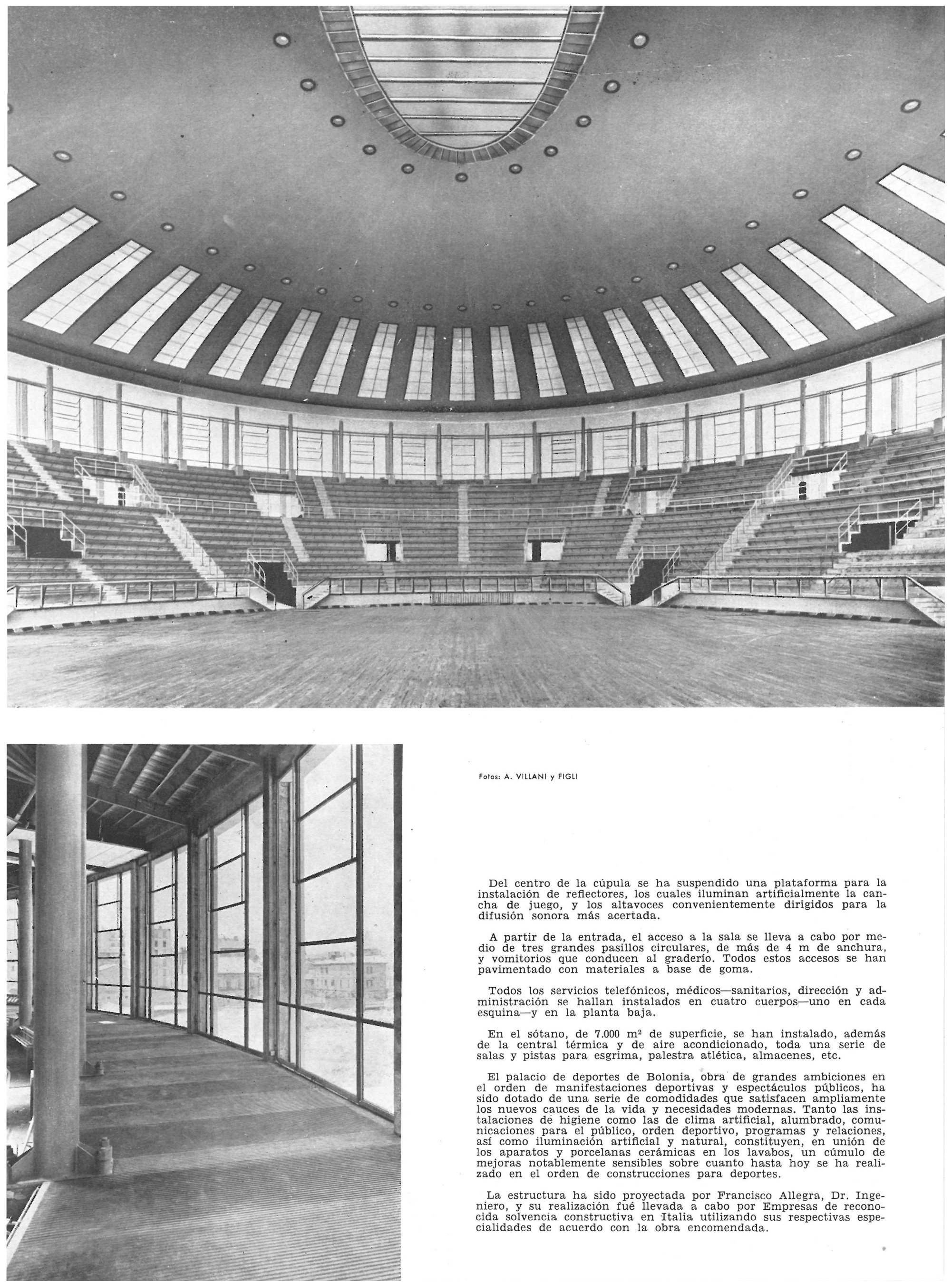

Fotos: A. VILLANI y FIGLI instalacion de reflectores, los cuales iluminan artificialmente la candifu de juego, y los altavoces convenientemente dirigidos para la dision sonora más acertada.

A partir de la entrada, el acceso a la sala se lleva a cabo por medio de tres grandes pasillos circulares, de más de $4 \mathrm{~m}$ de anchura, y vomitorios que conducen al graderio. Todos estos accesos se han pavimentado con materiales a base de goma.

Todos los servicios telefónicos, médicos-sanitarios, dirección y administración se hallan instalados en cuatro cuerpos-uno en cada esquina-y en la planta baja.

En el sótano, de $7.000 \mathrm{~m}^{2}$ de superficie, se han instalado, además de la central térmica y de aire acondicionado, toda una serie de salas y pistas para esgrima, palestra atlética, almacenes, etc.

El palacio de deportes de Bolonia, obra de grandes ambiciones en el orden de manifestaciones deportivas y espectáculos públicos, ha sido dotado de una serie de comodidades que satisfacen ampliamente os nuevos cauces de la vida y necesidades modernas. Tanto las instalaciones de higiene como las de clima artificial, alumbrado, comunicaciones para el publico, orden deportivo, programas y relaciones, asi como iluminacion artificial y natural, constituyen, en union de los aparatos y porcelanas ceránicas en los lavabos, un cúmulo de mejoras notablemente sensibles sobre cuanto hasta hoy se ha realizado en el orden de construcciones para deportes.

La estructura ha sido proyectada por Francisco Allegra, Dr. Ingeniero, y su realización fué llevada a cabo por Empresas de reconocialidades de acuerdo con la obra encomendada. 